\title{
Symptoms and problems with functioning among women and men with inoperable lung cancer-A longitudinal study
}

\author{
Malin Lövgren ${ }^{\mathrm{a}, b, *}$, Carol Tishelman ${ }^{\mathrm{c}, \mathrm{d}, \mathrm{h}}$, Mirjam Sprangers ${ }^{\mathrm{e}}$, Hirsh Koyi ${ }^{\mathrm{f}}$, \\ Katarina Hamberg ${ }^{g}$
}

a The Department of Neurobiology, Care Sciences and Society, Division of Nursing, Karolinska Institutet, Stockholm, Sweden

b School of Health and Social Sciences, Högskolan Dalarna, Falun, Sweden

c Stockholms Sjukhem Foundation, Research \& Development Unit/Palliative Care, Stockholm, Sweden

d School of Nursing, Midwifery and Social work, The University of Manchester, Manchester, United Kingdom

e Department of Medical Psychology, Academic Medical Center, University of Amsterdam, Amsterdam, The Netherlands

f The Department of Respiratory Medicine and Allergy, Karolinska University Hospital, Stockholm, Sweden

g The Department of Public Health and Clinical Medicine, Family Medicine, Umeå University, Umeå, Sweden

$\mathrm{h}$ The Department of Learning, Informatics, Management and Ethics, Medical Management Center, Karolinska Institutet, Stockholm, Sweden

Received 18 June 2007; received in revised form 7 September 2007; accepted 12 September 2007

\section{KEYWORDS \\ Lung neoplasm; Symptoms; Longitudinal study; Quality of life; Gender}

\begin{abstract}
Summary The aim of this study is to compare the prevalence and intensity of symptoms and problems with functioning between women and men with inoperable lung cancer (LC) during 3 months post-diagnosis. One hundred and fifty-nine patients completed the EORTC QLQ C$30+$ LC13 at three time points: close to diagnosis and prior to treatment, and one, and 3 months later. Descriptive cross-sectional analyses and longitudinal analyses using repeated measure ANOVA were conducted. These patients reported many and intense symptoms and problems with functioning. The most salient finding from the cross-sectional analysis was that women reported both more, and more intense problems with emotional functioning close to diagnosis. Statistically significant improvements over time were found in both men and women with regard to emotional functioning, dyspnea, insomnia, cough, pain in arm/shoulder, while physical functioning, fatigue, constipation, dysphagia, peripheral neuropathy and alopecia deteriorated significantly over time. The longitudinal analyses suggest that, with the exception of emotional functioning, gender differences were not only related to biological sex alone, but were also found to be related to other components of the patients' life situation, such as education, age, civil status and type of LC. Sensitivity to different symptom experiences and responses to
\end{abstract}

\footnotetext{
* Corresponding author at: School of Health and Social Sciences, Högskolan Dalarna, 79188 Falun, Sweden. Tel.: +46 23778428 ; fax: +46 23778080 .

E-mail address: malin.lovgren@ki.se (M. Lövgren).
} 
those experiences between and within women and men is also necessary in the management of symptoms in patients with inoperable LC.

(c) 2007 Elsevier Ireland Ltd. All rights reserved.

\section{Introduction}

Lung cancer (LC) is the leading cause of cancer-associated mortality worldwide among both women and men [1]. The high mortality rate is associated with advanced cancer at time of diagnosis, inhibiting curative treatment for most patients. Issues related to palliative care are therefore often important from diagnosis onward with treatment of symptoms as one essential aspect of such care. However, clinical research in patients with LC remains limited, although patients with LC are known to suffer from many and severe symptoms in comparison with other groups of cancer patients [2-5]. The severity of the disease and short survival time make longitudinal studies of symptom experience and quality of life (QoL) in LC even less common.

Over the past two decades, there has been a progressive shift in LC demographics with a marked increase in women patients [6,7]. Despite this change, most studies of symptoms and/or QoL in patients with LC are based on selected populations predominantly consisting of white, middle-income men with advanced LC [2]. Sarna's work on women with LC provides a notable exception [8-13]. Existing studies examining differences in symptom experience between women and men with LC are generally crosssectional, with inconclusive findings $[14,15]$. Some studies indicate that women report more $[4,16]$ and different symptoms than men $[17,18]$, whereas Krech et al. found marginal differences between women and men [19] and de Perrot et al. reported that women were less symptomatic at diagnosis than were men [20].

Ethnic minorities, elderly, and women patients all remain at risk for being relatively neglected in LC research [21]. Bias toward the inclusion of men in research studies often leads to limited generalizability of findings [22]. Other research, such as that on cardiovascular diseases, indicates that symptomatology is not always similar for women and men, and that lack of knowledge about differences in symptom experiences between them may hinder appropriate action from the health care system [23].

The lack of longitudinal data, the inconsistent findings on differences between women and men and the potential detrimental effect of these knowledge gaps on clinical practice, make further studies in symptom experiences in relation to gender over time important. In this article, we use the term gender when describing differences in symptomatology experienced by women and men, to indicate interactions between biological sex and psychological, social and cultural influences.

The aims of this study are therefore to examine (1) the prevalence and intensity of symptoms and problems with functioning among women and men with inoperable LC at three time points close to diagnosis; (2) the extent to which intensity of reported symptoms and problems with functioning change over time among women and men with inoperable LC; and (3) which patient characteristics influence the intensity of symptoms and problems with functioning in women and men over time.

\section{Patients and methods}

This study derives from a larger prospective longitudinal study of symptom experiences in a naturally occurring sample of patients with inoperable LC [24], based on 400 adults consecutively recruited close to time of diagnosis (mean 31 days, median 23 days) through the lung medicine departments of two university hospitals in the Stockholm region. The study was approved by the Regional research Ethics Review Board (KI 97-258, appendices 990503, 010220, 010731, 021212).

Staff at the lung medicine departments were asked to give patients a first information letter, with a copy also sent to the patient's home by the research team. A research nurse then contacted each patient to obtain informed consent for study participation. All data were collected in the presence of a research nurse, with efforts made for the same nurse to conduct data collection with the same patient at all time points. Data were collected at a venue determined by each patient, e.g. at homes, in hospital clinics or wards, at six time points: $\mathrm{T} 1$, close to diagnosis and prior to treatment; 2 weeks after T1; 1 month, 3 months, 6 months, and 1 year after T1. Patients completed a number of self-report instruments about symptom experiences at each time-point and were offered a 50 -sek gift certificate donated by COOP Sweden, which is a national federation of cooperative store, after completing each interview. Demographic and disease/treatment information was obtained from the patients and from registry data from the Regional Oncologic Centre.

As this is a severely ill patient group, a large degree of non-random attrition and non-participation was found, due to deteriorating health (see Fig. 1). We therefore selected a sub-group of patients who had completed instruments at the same three time points, to avoid using imputation techniques for the analyses. The analysis presented here is therefore based on data generated from all the 159 patients who had completed the EORTC QLQ C30 + LC13 at baseline (T1), 1 month (T2) and 3 months (T3) after T1.

\subsection{Self-reported data}

\subsubsection{EORTC QLQ-C 30 version $3.0+$ LC13}

This self-reported health-related quality of life (HRQL) instrument was developed as an integrated system for assessing HRQL for cancer patients participating in inter- 
Invited to participate: $\mathbf{N}=\mathbf{9 1 0}$ (428 women, 482 men)

\begin{tabular}{|l|l|}
\hline Not eligible for study & $\mathrm{N}=\mathbf{4 5}$ \\
\hline Cognitive problems & 14 \\
\hline Deceased before data collection & 31 \\
\hline Reason for nonparticipation & $\mathrm{N}=\mathbf{4 6 5}$ \\
\hline Declining participation and no reason specified & 151 \\
\hline "Too tired" to participate & 126 \\
\hline "Lack of time" & 50 \\
\hline "Poor physical condition" & 41 \\
\hline Could not be reached for response & 23 \\
\hline Critical of the study & 18 \\
\hline Other reason & 56 \\
\hline
\end{tabular}

Total participants in the main study: $\mathrm{N}=400$ (191 women, 209 men)

\section{Included in this sub-study: The largest amount of patients who completed EORTC QLQ at three time points post diagnosis including baseline $\mathrm{N}=159(70$ women, 89 men).}

\begin{tabular}{|c|c|c|c|}
\hline $\begin{array}{l}\text { Reason for attrition and missing } \\
\text { EORTC QLQ }\end{array}$ & $\begin{array}{l}\text { Close to } \\
\text { diagnosis and } \\
\text { prior to } \\
\text { treatment (T1) }\end{array}$ & $\begin{array}{l}\text { One month } \\
\text { after T1 }\end{array}$ & $\begin{array}{l}\text { Three months } \\
\text { after T1 }\end{array}$ \\
\hline $\begin{array}{l}\text { Deceased during data collection } \mathrm{N} \\
\text { (cumulative frequency) }\end{array}$ & - & $11(17)$ & $45(62)$ \\
\hline \multicolumn{4}{|l|}{ Reason for attrition in the main study } \\
\hline "Too tired" or "too ill" & - & 12 & 9 \\
\hline Critical of EORTC QLQ & - & 3 & - \\
\hline Unable to participate & - & 5 & 3 \\
\hline Unknown reasons & - & 5 & 2 \\
\hline Total & - & 25 & 14 \\
\hline Cumulative frequency & - & 44 & 58 \\
\hline Total included at each time point & $\mathrm{N}=245$ & $\mathrm{~N}=339$ & $\mathrm{~N}=280$ \\
\hline \multicolumn{4}{|c|}{ Missing EORTC QLQ at specific time point (but remain in the main study) } \\
\hline "Too tired" or "too ill" & - & 2 & 2 \\
\hline Critical to EORTC QLQ & - & - & - \\
\hline $\begin{array}{l}\text { Unable to participate at this time point } \\
\text { (e.g. out of town, not priority) }\end{array}$ & - & 4 & 5 \\
\hline Unknown reason & 3 & 7 & 1 \\
\hline Total & 3 & 13 & 8 \\
\hline $\begin{array}{l}\text { Total who completed EORTC QLQ at } \\
\text { time point }\end{array}$ & $\mathrm{N}=242$ & $N=326$ & $\mathrm{~N}=272$ \\
\hline
\end{tabular}

Fig. 1 Reasons for attrition and non-participation.

national clinical trials [25]. The core QoL questionnaire (QLQ-C30) assesses general aspects of HRQL through 30 items consisting of five functional scales (physical, role, cognitive, emotional and social), three symptom scales (fatigue, pain and nausea and vomiting), a global health status/QoL scale, and several single items (dyspnea, appetite, insomnia, constipation, diarrhea and perceived financial impact of the disease) [26]. A LC specific module (LC13) assesses disease-specific symptoms (cough, hemoptysis, dyspnea and site-specific pain), treatment-related side effects (sore mouth, dysphagia, peripheral neuropathy and alopecia) and pain medication [27]. Each item is assessed on a four-point Likert scale: (1) "not at all"; (2) "a little"; (3) "quite a bit"; (4) "very much", with the exception of the global health status/QoL items whose responses range from (1) "very poor" to (7) "excellent" [28]. The EORTC QLQ-
$\mathrm{C} 30+\mathrm{LC} 13$ have been found to be valid and useful tools, demonstrating sensitivity to change over time $[3,26,27]$. All scales and items except the global health/QoL scale were used in this study.

\subsubsection{Patient characteristics}

Data on the following demographic characteristics were collected: age, civil status (living with a partner; living without a partner), children (no children; live with children and/or have children $\leq 20$ years of age; have children $>20$ years of age or children not living at home), education level (<high school; high school or equivalent; >high school), and smoking habits (current smoker; ex-smoker; non-smoker). Known clinical characteristics include type of LC (SCLC; NSCLC), disease stage (I; II; IIla; IIIb; IV) and treatment received (chemotherapy alone; radiation therapy alone; concomitant 
chemotherapy and radiation therapy; both chemotherapy and radiation therapy; no treatment).

\section{Data analysis}

\subsection{A priori differences between women and men}

To examine differences between women and men in demographic and clinical data, $\chi^{2}$-tests (civil status, children, education, smoking habits, type of LC, cancer stage, treatment) and independent sample $t$-tests (age) were conducted. The same analysis methods were also used to compare demographic and clinical data from this sample with the sample from the larger study, and with the total population of patients with inoperable LC in Stockholm Sweden who were diagnosed during the same period.

\subsection{Prevalence and intensity of symptoms and problems with functioning between women and men}

The responses "a little", "quite a bit" and "very much" were combined to determine prevalence of symptoms and problems with functioning for each item. $\chi^{2}$-tests were used to test differences in prevalence between women and men. To examine intensity of symptoms and problems with functioning, all scores on the QLQ-C $30+\mathrm{LC} 13$ were linearly transformed to a $0-100$ scale [28]. Higher scores on functional scales represent a better level of functioning, while higher scores on the symptom scales represent higher level of symptomatology. Mean scores are reported as indicative of intensity. Cronbach's alpha values for physical, emotional, social functioning, pain, and dyspnea scales range from 0.75 to 0.85 , and for role functioning and fatigue scales $0.60-0.85$. The Cronbach's alpha of the cognitive functioning scale (CF) was $0.43-0.67$ and the nausea/vomiting scale (NV) between $0.20-0.78$. Due to these low values, we only analyzed the individual items of the CF and NV scales crosssectionally and do not use scales scores. Independent sample $t$-tests were used to test differences in intensity between women and men at each time point.

\subsection{Change in intensity of symptoms and problems over time}

Statistical changes in mean scale values were examined with repeated measure ANOVAs. Clinically meaningful changes were considered in accordance with recommendations from Osoba et al. [29], with a small change defined as a scale score change of $5-10$, moderate changes as $10-20$, and large change as $>20$.

\subsection{Influence of patients' characteristics on change in intensity of symptoms and problems}

In the repeated measure ANOVA both within and between subjects effects were taken into account. Our focus was on differences between women and men, so in addition to biological sex, the following variables were included in the analysis to examine possible gender-related interactions: age ( $<65$ years; $65-74$ years; $>74$ years), civil status, children, education level and type of LC. The longitudinal analyses were conducted in several steps. First, variables were added separately into the analysis. Second, interaction effects were considered and added into the analysis model. In the third step, statistically significant changes $(p \leq 0.05)$ were examined. As a fourth step, we used Box's $M$ test and Mauchly's test of sphericity to test the assumption of the models. Cook's distance was also used to examine possible influence of individual observations, and residual plots were examined. As a final step, clinically meaningful changes were considered (as described above). Partial etasquared were also used to examine the proportion of the total variance that could be explained by factors included in the ANOVAs.

\section{Results}

\subsection{Patient demographic and clinical characteristics}

As shown in Table 1, women were significantly younger and lived without a partner more often than did men. Most patients had less than high school education. A majority of patients were diagnosed with NSCLC, stages IIla-IV. Ten percent of the patients $(N=16)$ were deemed inoperable due to tumor localization or co-morbidity rather than disease stage. Women received chemotherapy alone and in combination with radiotherapy more often than men $(p=0.013$, not shown in Table 1), whereas men did not receive any oncologic treatment more often than women. Patients receiving concomitant therapy were significantly younger than those did not $(p=0.05$, not shown in Table 1$)$.

This sub-sample $(n=159)$ differed demographically and clinically from those in the larger study $(N=400-159)$, in that men were significantly older $(p=0.036)$, received more radiation $(p=0.037)$ and concomitant therapy $(p=0.007)$, but less chemotherapy alone $(p=0.038)$ than men in the full sample. More women had LC stage IIla $(p=0.031)$ and received radiation therapy $(p=0.001)$, with fewer not receiving any treatment $(p=0.001)$, than was the case for women in the full sample. This sub-sample also had longer survival times compared with the full sample $(p=0.001)$.

This sample also differed from patients with inoperable LC in Stockholm Sweden diagnosed during the same time period in the Stockholm-Gotland Cancer Registry. Our sample was younger (mean age Cancer Registry population: 68.8 years, our sample: 66 years) and survived longer (mean survival Cancer Registry population: 178 days, our sample: 443 days) than registry population. This may be due to the Registry's inclusion of patients diagnosed in non-university hospital settings.

\subsection{Symptoms and problems with functioning}

4.2.1. Prevalence and intensity of symptoms and problems with functioning between women and men 4.2.1.1. Prevalence. Tables $2 \mathrm{a}$ and $2 \mathrm{~b}$ present those symptoms and problems with functioning reported by $>50 \%$ of 
Table 1 Demographic and clinical characteristics

\begin{tabular}{|c|c|c|c|}
\hline & Women, $N=70$ (44\%) & Men, $N=89(56 \%)$ & $p$-Value \\
\hline \multicolumn{4}{|l|}{ Age } \\
\hline Mean (S.D.) & $63.4(9.3)$ & $68.9(10.5)$ & $<0.001$ \\
\hline Minimum-maximum & $42-84$ & 47-95 & \\
\hline Median & 61 & 67 & \\
\hline$<65$ years, $N(\%)$ & $43(61.4)$ & $39(43.8)$ & \\
\hline $65-74$ years & $18(25.7)$ & $23(25.8)$ & \\
\hline$>74$ years & $9(12.9)$ & $27(30.3)$ & \\
\hline \multicolumn{4}{|l|}{ Civil status, $N(\%)$} \\
\hline Live without a partner & $33(48.5)$ & $28(31.5)$ & $<0.01$ \\
\hline Married or cohabiting & $35(51.5)$ & $61(68.5)$ & \\
\hline Missing & 2 & 0 & \\
\hline \multicolumn{4}{|l|}{ Children, $N(\%)$} \\
\hline No children & $8(11.4)$ & $17(19.1)$ & \\
\hline Live together with children or have children $\leq 20$ years of age & $8(11.4)$ & $12(13.5)$ & \\
\hline Have children but not $\leq 20$ years of age or children living at home & $54(77.1)$ & $60(67.4)$ & \\
\hline \multicolumn{4}{|l|}{ Education, $N(\%)$} \\
\hline$>$ High school & $18(26.5)$ & $26(29.9)$ & \\
\hline High school or equivalent (12 years) & $11(16.2)$ & $11(12.6)$ & \\
\hline$<$ High school ( 9 years) & $39(57.4)$ & $50(57.5)$ & \\
\hline Missing & 2 & 2 & \\
\hline \multicolumn{4}{|l|}{ Smoking habits, $N(\%)$} \\
\hline Current smoker & $36(51.4)$ & $41(46.1)$ & \\
\hline Ex-smoker & $13(18.6)$ & $22(24.7)$ & \\
\hline Non-smoker & $3(4.3)$ & $3(3.4)$ & \\
\hline Missing & $18(25.7)$ & $23(25.8)$ & \\
\hline \multicolumn{4}{|l|}{ Type of lung cancer, $N$ (\%) } \\
\hline $\mathrm{SCLC}$ & $11(15.9)$ & $13(14.8)$ & \\
\hline NSCLC & $58(84.1)$ & $75(85.2)$ & \\
\hline Missing & 1 & 1 & \\
\hline \multicolumn{4}{|l|}{ Stage of disease, $N(\%)$} \\
\hline 1 & $3(4.3)$ & $5(5.6)$ & \\
\hline II & $3(4.3)$ & $5(5.6)$ & \\
\hline IIla & $11(15.7)$ & $10(11.2)$ & \\
\hline IIIb & $13(18.6)$ & $17(19.1)$ & \\
\hline IV & $27(38.6)$ & $31(34.8)$ & \\
\hline Unclassified tumor & $3(4.3)$ & $5(5.6)$ & \\
\hline Missing & 10 & 16 & \\
\hline \multicolumn{4}{|l|}{ Treatment received, $N(\%)$} \\
\hline Chemotherapy alone $(\mathrm{Ct})$ & $36(51.4)$ & $31(34.8)$ & $<0.05$ \\
\hline Radiation therapy alone (Rt) & $9(12.9)$ & $18(20.2)$ & \\
\hline Concomitant $\mathrm{Ct}+\mathrm{Rt}$ & $10(14.3)$ & $19(21.3)$ & $<0.01$ \\
\hline Both $\mathrm{Ct}+\mathrm{Rt}$ & $15(21.4)$ & $13(14.6)$ & \\
\hline No treatment & 0 & $8(9.0)$ & \\
\hline
\end{tabular}

women and men respectively at each time point. The most prevalent symptoms and problems with functioning were associated with fatigue at all time points for both women and men (Tables $2 \mathrm{a}$ and $2 \mathrm{~b}$ ). Other common symptoms and problems with functioning among women and men at these three time points were associated with physical functioning, emotional functioning, dyspnea, role functioning, cough, pain and social functioning. Men also reported insomnia as one of the most common symptoms at all time points, while women commonly reported appetite loss at all time points. Of 40 items assessed, an average of 20 items per patient was reported at baseline (T1) and after 1 month (T2), and 21 items per patient 3 months after baseline (T3). Between $43 \%$ and $47 \%$ of the sample reported having pain for which they received medication, with medication reported as providing relief in 14\% of these patients at T1, 24\% at T2, and 33\% at T3 (data not shown). 
Table $2 \mathrm{a}$ Most prevalent symptoms and problems with functioning at three time points post-diagnosis among women (prevalence $>50 \%$ ).

\begin{tabular}{|c|c|c|c|c|c|}
\hline \multicolumn{2}{|l|}{ Baseline (T1), $N=70$} & \multicolumn{2}{|l|}{ One month after baseline (T2), $N=70$} & \multicolumn{2}{|l|}{ Three months after baseline (T3), $N=70$} \\
\hline Scale, item & Prevalence (\%) & Scale, item & Prevalence & Scale, Item & Prevalence \\
\hline FA, tired & 88 & FA, tired & 93 & FA, tired & 93 \\
\hline EF, depressed & 86 & PF, trouble doing strenuous activities & 90 & PF, trouble doing strenuous activities & 90 \\
\hline PF, trouble doing strenuous activities & 83 & $\mathrm{PF}$, trouble taking a long walk & 90 & $\mathrm{FA}$, need to rest & 90 \\
\hline FA, need to rest & 83 & FA, need to rest & 89 & PF, trouble taking a long walk & 84 \\
\hline EF, worry & 83 & DY, short of breath climbing stairs & 87 & $\begin{array}{l}\text { RF, limited doing work or other daily } \\
\text { activities }\end{array}$ & 84 \\
\hline FA, felt weak & 81 & $\begin{array}{l}\text { PF, need to stay in bed/chair during } \\
\text { the day }\end{array}$ & 86 & FA, felt weak & 84 \\
\hline DY, short of breath climbing stairs & 80 & FA, felt weak & 84 & $\begin{array}{l}\text { PF, need to stay in bed/chair during } \\
\text { the day }\end{array}$ & 81 \\
\hline DY, short of breath while walking & 79 & DY, short of breath while walking & 80 & $\begin{array}{l}\text { RF, limited in pursuing hobbies or } \\
\text { leisure activities }\end{array}$ & 79 \\
\hline DY, short of breath & 78 & $\begin{array}{l}\text { RF, limited doing work or other daily } \\
\text { activities }\end{array}$ & 75 & DY, short of breath climbing stairs & 77 \\
\hline $\begin{array}{l}\text { RF, limited doing work or other daily } \\
\text { activities }\end{array}$ & 77 & EF, worry & 74 & DY, short of breath & 76 \\
\hline EF, feel tense & 75 & $\begin{array}{l}\text { RF, limited in pursuing hobbies or } \\
\text { leisure time activities }\end{array}$ & 73 & DY, short of breath while walking & 74 \\
\hline Cough & 74 & EF, depressed & 69 & $\begin{array}{l}\text { SF, if physical condition or medical } \\
\text { treatment have interfered with social } \\
\text { activities }\end{array}$ & 69 \\
\hline PF, trouble taking a long walk & 74 & Cough & 69 & EF, worry & 68 \\
\hline $\begin{array}{l}\text { PF, need to stay in bed/chair during } \\
\text { the day }\end{array}$ & 70 & EF, feel tense & 66 & Cough & 67 \\
\hline $\begin{array}{l}\text { RF, limited in pursuing hobbies or } \\
\text { leisure time activities }\end{array}$ & 66 & $\begin{array}{l}\text { SF, if physical condition or medical } \\
\text { treatment have interfered with social } \\
\text { activities }\end{array}$ & 66 & EF, feel irritable & 66 \\
\hline SL, trouble sleeping & 63 & SL, trouble sleeping & 58 & $\mathrm{EF}$, depressed & 66 \\
\hline $\begin{array}{l}\text { SF, if physical condition or medical } \\
\text { treatment have interfered with } \\
\text { social activities }\end{array}$ & 61 & AP, appetite loss & 57 & PF, short walk outside & 56 \\
\hline AP, appetite loss & 56 & $\begin{array}{l}\text { SF, if physical condition or medical } \\
\text { treatment have interfered with your } \\
\text { family life }\end{array}$ & 54 & PA, pain & 55 \\
\hline PA, pain outside chest/arm/shoulder & 56 & Alopecia & 53 & AP, appetite loss & 53 \\
\hline $\mathrm{PA}$, pain & 55 & PA, pain outside chest/arm/shoulder & 53 & PA, pain outside chest/arm/shoulder & \\
\hline EF, feel irritable & 52 & $\mathrm{EF}$, feel irritable & 51 & Alopecia & 51 \\
\hline
\end{tabular}


Table $2 \mathrm{~b}$ Most prevalent symptoms and problems with functioning at three time points post-diagnosis among men (prevalence $>50 \%$ )

\begin{tabular}{|c|c|c|c|c|c|}
\hline \multicolumn{2}{|l|}{ Baseline (T1), $N=89$} & \multicolumn{2}{|l|}{ One month after baseline (T2), N= 89} & \multicolumn{2}{|l|}{ Three months after baseline (T3), N= 89} \\
\hline Scale, item & Prevalence (\%) & Scale, item & Prevalence & Scale, item & Prevalence \\
\hline FA, tired & 86 & FA, tired & 90 & FA, tired & 91 \\
\hline FA, need to rest & 85 & FA, need to rest & 84 & PF, trouble taking a long walk & 88 \\
\hline DY, short of breath climbing stairs & 82 & PF, trouble doing strenuous activities & 80 & FA, need to rest & 86 \\
\hline Cough & 79 & DY, short of breath climbing stairs & 80 & $\mathrm{PF}$, trouble doing strenuous activities & 84 \\
\hline DY, short of breath & 78 & DY, short of breath & 79 & FA, felt weak & 83 \\
\hline FA, felt weak & 74 & PF, trouble taking a long walk & 78 & DY, short of breath while walking & 83 \\
\hline PF, trouble doing strenuous activities & 73 & FA, felt weak & 75 & DY, short of breath & 82 \\
\hline DY, short of breath while walking & 71 & Cough & 75 & DY, short of breath climbing stairs & 82 \\
\hline PF, trouble taking a long walk & 69 & DY, short of breath while walking & 73 & $\begin{array}{l}\text { RF, limited doing work or other daily } \\
\text { activities }\end{array}$ & 75 \\
\hline EF, worry & 69 & $\begin{array}{l}\text { RF, limited doing work or other daily } \\
\text { activities }\end{array}$ & 70 & $\begin{array}{l}\text { RF, limited in pursuing hobbies or } \\
\text { leisure time activities }\end{array}$ & 74 \\
\hline $\begin{array}{l}\text { PF, need to stay in bed/chair during } \\
\text { the day }\end{array}$ & 67 & $\begin{array}{l}\text { PF, need to stay in bed/chair during } \\
\text { the day }\end{array}$ & 69 & $\begin{array}{l}\text { PF, need to stay in bed/chair during } \\
\text { the day }\end{array}$ & 73 \\
\hline EF, depressed & 64 & $\begin{array}{l}\text { RF, limited in pursuing hobbies or } \\
\text { leisure time activities }\end{array}$ & 65 & Cough & 72 \\
\hline $\begin{array}{l}\text { RF, limited doing work or other daily } \\
\text { activities }\end{array}$ & 63 & $\mathrm{EF}$, worry & 61 & EF, feel irritable & 65 \\
\hline $\begin{array}{l}\text { RF, limited in pursuing hobbies or } \\
\text { leisure time activities }\end{array}$ & 63 & PA, pain & 57 & $\begin{array}{l}\text { SF, if physical condition or medical } \\
\text { treatment have interfered with social } \\
\text { activities }\end{array}$ & 63 \\
\hline EF, feel irritable & 63 & EF, feel irritable & 57 & $\mathrm{CF}$, difficulty remembering things & 61 \\
\hline PA, pain & 60 & $\begin{array}{l}\text { SF, if physical condition or medical } \\
\text { treatment have interfered with social } \\
\text { activities }\end{array}$ & 57 & PA, pain & 59 \\
\hline SL, trouble sleeping & 59 & EF, depressed & 55 & PF, short walk outside & 57 \\
\hline EF, feel tense & 59 & SL, trouble sleeping & 53 & EF, worry & 57 \\
\hline CF, difficulty remembering things & 51 & $\mathrm{CF}$, difficulty remembering things & 52 & Chest pain & 56 \\
\hline \multirow[t]{4}{*}{ Chest pain } & 51 & $\mathrm{EF}$, feel tense & 51 & $\begin{array}{l}\text { SF, if physical condition or medical } \\
\text { treatment have interfered with your } \\
\text { family life }\end{array}$ & 54 \\
\hline & & & & EF, depressed & 53 \\
\hline & & & & SL, trouble sleeping & 51 \\
\hline & & & & $\mathrm{EF}$, feel tense & 51 \\
\hline
\end{tabular}

FA: fatigue; PF: physical functioning; RF: role functioning; DY: dyspnea; SL: insomnia; AP: appetite loss; CO: constipation; FI: financial difficulties; SF: social functioning; EF: emotional functioning; PA: pain; CF: cognitive functioning. 
Table 3 The intensity in symptom and functional scales at three time points following diagnosis

\begin{tabular}{|c|c|c|c|c|c|c|}
\hline \multirow[t]{2}{*}{ QLQ C-30 } & \multicolumn{2}{|l|}{ Baseline (T1) } & \multicolumn{2}{|c|}{ One month after T1 (T2) } & \multicolumn{2}{|c|}{ Three months after T1 (T3) } \\
\hline & $\begin{array}{l}\text { Women, } N=70 \text {, } \\
\text { mean (S.D.) }\end{array}$ & $\begin{array}{l}\text { Men, } N=89 \\
\text { mean (S.D.) }\end{array}$ & $\begin{array}{l}\text { Women, } N=70 \text {, } \\
\text { mean (S.D.) }\end{array}$ & $\begin{array}{l}\text { Men, } N=89, \\
\text { mean (S.D.) }\end{array}$ & $\begin{array}{l}\text { Women, } N=70 \text {, } \\
\text { mean (S.D.) }\end{array}$ & $\begin{array}{l}\text { Men, } N=89, \\
\text { mean (S.D.) }\end{array}$ \\
\hline Physical functioning & $67.0(22.0)$ & $73.0(21.3)$ & $66.6(19.7)$ & $69.5(22.0)$ & $63.3(21.3)$ & $62.2(23.8)$ \\
\hline Role functioning & $52.8(34.6)$ & $60.2(34.3)$ & $51.4(32.8)$ & $57.1(33.6)$ & $50.2(31.7)$ & $50.2(33.0)$ \\
\hline Emotional functioning & $61.7(24.6)^{*}$ & $69.4(22.5)^{*}$ & $68.8(23.0)$ & $75.2(20.9)$ & $69.6(24.7)$ & $74.3(21.4)$ \\
\hline Social functioning & $69.5(28.5)$ & $74.9(28.3)$ & $69.5(28.5)$ & $73.6(26.3)$ & $70.7(25.8)$ & $68.9(28.6)$ \\
\hline Fatigue & $46.8(27.2)$ & $42.0(24.0)$ & $48.9(26.4)$ & $43.7(25.2)$ & $50.6(25.5)$ & $49.2(27.3)$ \\
\hline Pain & $26.2(28.9)$ & $26.5(26.3)$ & $25.7(27.8)$ & $26.4(28.8)$ & $23.6(27.9)$ & $28.5(28.6)$ \\
\hline Dyspnoea & $47.3(35.9)$ & $46.8(33.2)$ & $43.8(31.9)$ & $40.8(30.5)$ & $44.3(33.4)$ & $46.4(32.4)$ \\
\hline Insomnia & $38.1(36.9)$ & $34.1(35.0)$ & $27.5(27.9)$ & $28.1(31.3)$ & $23.3(30.7)$ & $26.2(29.9)$ \\
\hline Appetite loss & $32.9(36.1)$ & $23.1(30.9)$ & $32.9(33.8)$ & $23.2(30.3)$ & $30.5(35.3)$ & $28.5(34.7)$ \\
\hline Constipation & $19.5(32.8)$ & $16.7(28.6)$ & $23.8(33.6)$ & $23.2(29.5)$ & $21.4(31.1)$ & $25.8(31.5)$ \\
\hline Diarrhoea & $7.7(19.9)$ & $7.7(19.9)$ & $9.0(21.2)$ & $9.7(22.0)$ & $11.4(25.3)$ & $7.3(16.4)$ \\
\hline Financial difficulties & $21.4(33.1)$ & $14.7(26.8)$ & $16.7(28.2)$ & $12.7(25.9)$ & $17.1(30.9)$ & $12.7(25.9)$ \\
\hline \multicolumn{7}{|l|}{ LC-13 } \\
\hline Coughing & $37.7(29.6)$ & $36.0(25.0)$ & $29.5(24.4)$ & $32.6(24.1)$ & $34.8(31.3)$ & $34.5(28.2)$ \\
\hline Haemoptysis & $5.2(13.5)$ & $7.6(18.7)$ & $3.8(15.6)$ & $4.1(12.1)$ & $5.3(19.5)$ & $3.0(9.6)$ \\
\hline Dyspnoea & $35.3(24.9)$ & $31.8(21.8)$ & $34.0(23.3)$ & $29.7(22.4)$ & $32.0(24.0)$ & $34.5(24.1)$ \\
\hline Sore mouth & $4.3(14.9)$ & $3.8(14.7)$ & $8.6(20.2)$ & $4.9(16.4)$ & $10.0(20.7)$ & $4.9(13.8)$ \\
\hline Dysphagia & $8.6(19.4)$ & $6.8(16.1)$ & $8.6(17.7)$ & $9.7(21.4)$ & $17.6(29.3)$ & $16.5(30.2)$ \\
\hline Peripheral neuropathy & $10.0(22.2)$ & $11.1(20.8)$ & $16.7(27.7)$ & $18.4(26.6)$ & $18.6(31.4)$ & $18.0(26.6)$ \\
\hline Alopecia & $1.4(6.8)$ & $1.9(7.8)$ & $35.7(39.9)^{*}$ & $22.1(34.8)^{*}$ & $35.7(41.0)$ & $30.7(39.0)$ \\
\hline Pain in chest & $18.9(26.7)$ & $22.3(24.6)$ & $12.3(18.1)^{*}$ & $20.2(24.4)^{*}$ & $16.4(24.0)$ & $22.6(23.0)$ \\
\hline Pain in arm or shoulder & $24.5(31.3)$ & $19.9(28.5)$ & $16.2(25.2)$ & $15.5(23.7)$ & $14.5(23.9)$ & $17.2(27.1)$ \\
\hline Pain outside chest and arm/shoulder & $27.5(29.4)$ & $25.4(34.4)$ & $31.6(33.6)^{*}$ & $20.8(30.4)^{*}$ & $27.8(32.0)$ & $27.3(34.0)$ \\
\hline
\end{tabular}


Significantly more women than men reported "feeling tense" $(p=0.032)$, "worried" $(p=0.045)$, "depressed" $(p=0.003)$ and more limited in work/daily activities $(p=0.048)$ at baseline. Significantly more women than men also reported that their physical condition or treatments interfered with their social activities at T1 $(p=0.038$, women $61 \%$, men $45 \%$ ). At 1 month following baseline, significantly more women than men reported needing to stay in bed or in a chair most of the day $(p=0.013)$. Women also reported significantly more alopecia at $\mathrm{T} 2$ than did men $(p=0.033$, women $53 \%$, men $36 \%$ ). At 3 months following baseline, significantly more men than women reported memory problems ( $p=0.04$, men $61 \%$, women $44 \%)$ and chest pain $(p=0.013$, men $56 \%$, women $36 \%)$.

4.2.1.2. Intensity. Women reported a lower level of emotional functioning at baseline than men (Table 3). Women reported a higher level of alopecia and pain outside the chest and arm/shoulder than men at 1 month following baseline. However, chest pain was reported as more intense by men than women at this time point.

\subsubsection{Change in intensity of symptoms and problems} over time

A time effect was found for two functional scales and four symptom scales of the QLQ C-30, and five symptoms scales of the LC-13 (Fig. 2a-C). Improvements were found with regard to emotional functioning (Fig. 2a), dyspnea, insomnia, cough and pain in arm/shoulder (Fig. 2b). Deterioration over time was found with regard to physical functioning (Fig. 2a), fatigue, constipation, dysphagia, peripheral neuropathy and alopecia over time (Fig. 2c). These changes were found to be both statistically significant and clinically meaningful.

\subsubsection{Influence of patients' characteristics on change in intensity of symptoms and problems}

Factors found to influence the symptom and functional scales over time are shown in Table 4. All factors named below were found to be both statistically significant and clinically meaningful. In general, a low proportion $(<10 \%)$ of variance was explained by the factors included in the models. An exception was that time explained $28 \%$ of the variance in regard to the treatment-related side-effect alopecia.

4.2.3.1. The effects of gender and/or other patients' characteristics in interaction with gender. An interaction between gender and educational level was found in relation to role functioning. The greatest differences between women and men were found in the two subgroups with highest education, with men found to have better role functioning than women at baseline and 1 month later (Table 4). Emotional functioning was reported as better among men than among women over time. Dyspnea improved in men over time, while women showed an improvement at 1 month post-baseline followed by deterioration at 3 months after baseline. Cough differed by both gender and age group in that cough improved in both women and men 74 years and older; improved for women but deteriorated for men in ages 65-74; improved 1 month following baseline and deteriorated at 3 months following baseline for both women and men aged $<65$ years. Men who lived without a partner reported more intense pain outside the chest and

\section{(a) Physical-and Emotional Functioning over time}

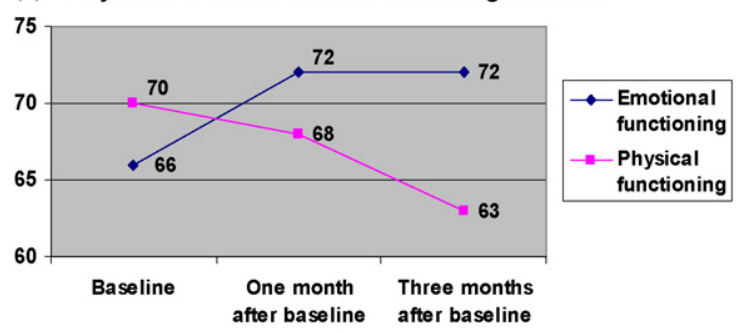

Symptom scales

(b) Mean scores indicating improvement

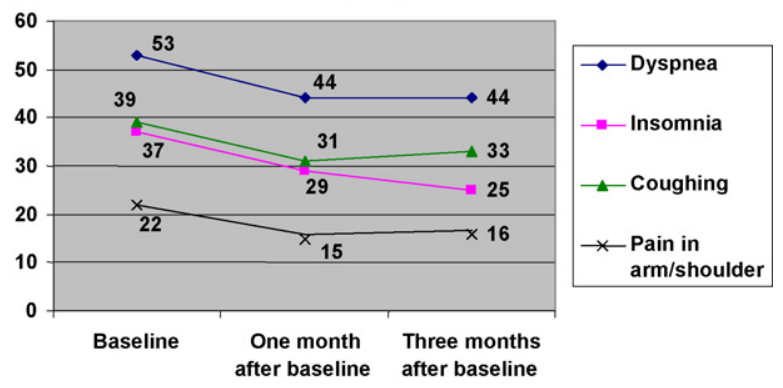

Symptom scales

(c) Mean scores indicating deterioration

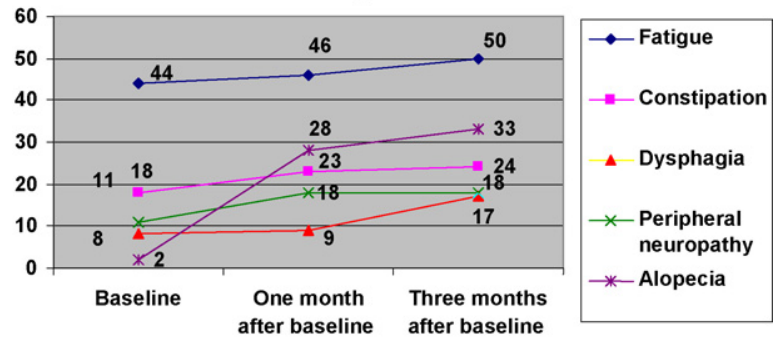

Fig. 2 (a) The functional scales over time. Higher mean score represent better level of functioning. (b) Symptoms that improved over time. Higher mean score represent higher level of symptom. (c) Symptoms that deteriorated over time. Higher mean score represent higher level of symptom.

$\mathrm{arm} /$ shoulder than did women who lived without a partner. 4.2.3.2. The effects of other patients' characteristics. Role functioning deteriorated over time in those patients with lowest levels of education (Table 4). Appetite loss was reported as more intense over time in those patients who lived with a partner compared with those who did not, whereas pain outside chest, arm and/or shoulder was reported as more intense among those who lived without a partner than those with a partner. Insomnia was reported as more intense over time in patients without children compared with those who had children. Dyspnea was reported as more intense in patients with SCLC at baseline than patients with NSCLC.

\section{Discussion}

This study investigated similarities and differences in symptom experience in women and men with inoperable LC over time. The results confirm that patients with LC have many and varied symptoms, as noted previously $[2,14,30]$. It should be recognized that the included patients represent 


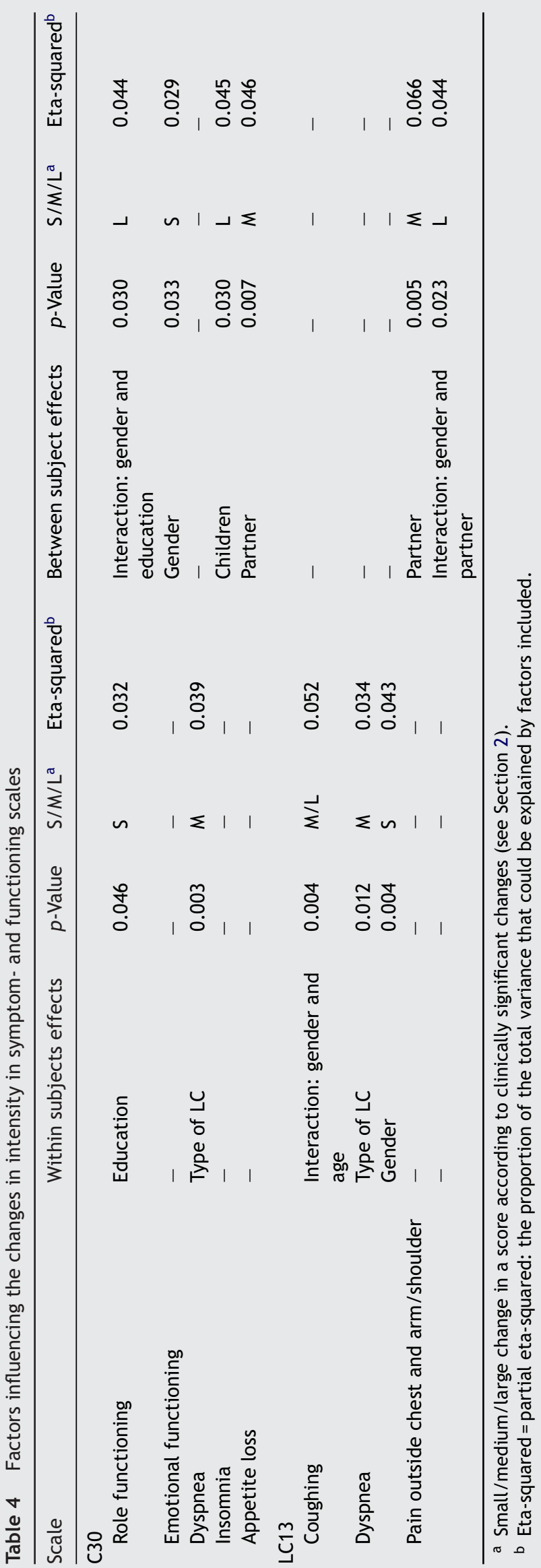

the "healthiest" of these very sick patients, with access to university health care at low out-of-pocket costs. This implies that the problems described might under-represent those experienced by many other patients with inoperable LC. Some differences between women and men regarding symptoms and problems with functioning were found, although the longitudinal analyses suggest that gender differences were not always related to biological sex alone, but may also be related to other components of the patients' life situation, such as education, age, civil status and type of LC.

The previously reported inconsistent results on differences between women and men in symptom experiences in LC literature $[14,15]$ might be related to differences in the aspects of symptom experiences assessed, patients groups examined, study designs used and data collection approaches. For example, Degner and Sloan [4] and Oh [16] used the same self-report instrument, Symptom Distress Scale, and found the same trend, with women reporting more symptomatology than men in general. On the other hand, using different data collection approaches de Perrot et al. found that women were less symptomatic at diagnosis than were men [20], while Krech et al. found marginal differences between women and men [19]. Direct comparison between studies may thus be hindered by such differences.

A number of results from this study are noteworthy. As is the case in EORTC C30 reference data from the Swedish general population [31], women reported poorer emotional functioning than men. Many men in developed countries have been socialized such that reporting symptoms or discomfort are seen as signs of weakness [32], and might therefore underreport symptoms and problems. Other patterns of gender differences deviated from those found in the Swedish population data [31], and therefore may be more disease specific. It should be noted that no major differences between women and men were found in this study, raises the possibility that major differences might not exist at this stage of the disease. It is also possible that differences exist in this patient group, but that these issues are not included in the questionnaire used in the study. It should also be recognized that the emotional functioning was worst closest to diagnosis, which may be a result of a reaction to diagnosis, which in turn might also influence social life and insomnia as shown in the results.

We have no clear explanation for the influence of biological sex and education on role functioning, but it should be recognized that many of the women studied here belong to the "housewife generation" or the "mixed generation", indicating that a great majority have primary responsibility for household-related activities [33]. In this age group women may maintain the responsibility while other employment related roles have been relinquished by both women and men. Another possible explanation might be that patients with least education have daily activities demanding high level of physical functioning.

Appetite loss was reported as more intense in those who lived with a partner than those without, which might suggest that this symptom becomes more obvious in interaction with other people. This explanation is supported by several studies indicating problematic social interactions around eating between people with advanced cancer and their partners [34-36]. Pain outside chest, arm and/or shoulder was also influenced by if the living situation of the patient (with 
a partner or not), with those living alone reporting more pain. In general, living alone has been found to be a factor of significance for pain experiences [37]. Why this pattern should be more pronounced for men than for women who live alone is unclear. One hypothesis might be that Western men tend to provide, receive, and seek less social support than women in dealing with such problems $[32,38]$. One possible explanation for the finding that patients with children had less insomnia might also be related to social support, as many in this patient group have adult children.

This study found that pain was one of the most prevalent symptoms at each time point for both women and men, with nearly half the patients reporting some medicating for pain. It is notable that many patients reported no relief from pain medication close to diagnosis, with more patients reporting help of medication over time. It is possible that this may indicate that patients initially self-medicate, but receive more professional help over time; however this help seems still insufficient.

As this study was designed with a naturally occurring rather than treatment-based sample, treatment was not included in these explorative analyses, due to differences in timing of treatment regimes. It should be recognized that much of the deterioration and improvement in functioning and symptoms over time found in this study may well be explained by disease progression and treatment. As a low proportion of variance was explained by the included variables, it is likely that inclusion of treatment as well as other more individually or clinically related variables would better explain variance. It should also be recognized that there are interrelationships between age, gender and treatment in our sample, in that women are younger and receive more chemotherapeutic treatment, and younger patients were found to receive more concomitant therapy. A number of results, e.g. dyspnea, coughing and alopecia, may be related to this.

We did not evaluate confounders such as age and civil status in the cross-sectional analyses, due to the small number of patients in each group and close relationships between variables. These close relationships mirror the life situation of women and men in Sweden today, for example, with more elderly women living longer and alone [39]. Other factors that might influence symptom experience include disease stage and smoking habits, factors that were not included in the analyses. As this was a sample of inoperable patients, few were diagnosed in early stages. Data on smoking habits was obtained via the regional Oncologic Center, with large amounts of missing data prohibiting its use. This is notable, since this question is part of the form to be completed by examining physicians, in an otherwise comprehensive data registry.

Despite the social welfare system in Sweden, with low out-of-pocket costs for patients, both women and men reported that their physical condition or medical treatment impacted on their economic situation slightly more than was the case in Swedish population data [31], indicating same degree of financial constraint for these patients. In this study, severe health problems are combined with relatively low levels of education, which may suggest that this group may be particularly vulnerable due to low income. Michelson et al. [31] pointed out that financial constrains can be expected to affect all aspects of QoL and mapping of financial constraints should therefore be thorough, even in Sweden.

Because of the number of statistical tests conducted it is also possible that some differences found are artifacts. Instead of lowering the $p$-value and risk missing existing differences in this explorative study, we examined clinical relevance. Another important reason for examine clinical relevance was that statistical significant changes in a score do not necessarily indicate clinically meaningful changes. Little consensus about how scores should be interpreted exists, and clinical significance is a subjective judgment [25]. Guyatt et al. [40] pointed out that even while considerable work has been accomplished around interpretation of QoL measures, much remains to do. Clinically meaningful changes in a score were interpreted here according to Osoba et al.'s "subjective significance"' [29], but this may underestimate clinical relevance as other investigators have found that changes between $5 \%$ and $10 \%$ are noticed by patients who regard them as "significant" [25]. King [41] importantly points out that the definition of a "large" change in a score by scale varies for patients.

\section{Clinical implications}

This study suggests that except for emotional functioning were women report both more and more intense negative emotional reactions, we found no major differences in prevalence and intensity of symptoms and problems with functioning in this sample of men and women with inoperable LC. It should be recognized that it is likely that there is no standard level of intensity at which interventions are necessary; rather different symptoms may need interventions at different levels of severity, although this has not be well investigated. Sensitivity to different symptom experiences and responses to those experiences between and within group of women and men is also necessary.

\section{Conflict of interest statement}

There are no conflicts of interest regarding this article.

\section{Acknowledgements}

Funding for this project has been gratefully received from the Swedish Cancer Society, the Swedish Research Council, the Health Care Sciences Post Graduate School at Karolinska Institutet, the Swedish Heart-Lung Foundation, the Swedish Foundation for Health Care Sciences and Allergy Research and COOP Sweden.

\section{References}

[1] Tewari KS, Disaia PJ. Lung and bronchus cancer in women: a 21st-century epidemic. Clin Obstet Gynecol 2002;45:784-811.

[2] Cooley ME. Symptoms in adults with lung cancer: a systematic research review. J Pain Symptom Manage 2000;19:137-53.

[3] Montazeri A, Gillis CR, McEwen J. Quality of life in patients with lung cancer. A review of literature from 1970 to 1995. Chest 1998;113:467-81. 
[4] Degner LF, Sloan JA. Symptom distress in newly diagnosed ambulatory cancer patients and as a predictor of survival in lung cancer. J Pain Symptom Manage 1995;10:423-31.

[5] Lindstone V, Butters E, Seed PT, Sinnott C, Beynon T, Richards M. Symptoms and concerns amongst cancer outpatients: identifying the need for specialist palliative care. Palliative Med 2003;17:588-95.

[6] Janssen-Heijnen MLG, Coebergh J-WW. The changing epidemiology of lung cancer in Europe. Lung Cancer 2003;41:245-58.

[7] Patel JD. Lung cancer in women. J Clin Oncol 2005;23:3212-8.

[8] Sarna L. Correlates of symptom distress in women with lung cancer. Cancer Practice 1993;1:21-8.

[9] Sarna L. Smoking behaviors of women after diagnosis with lung cancer. J Nurs Scholarship 1995;27:35-41.

[10] Sarna L. Women with lung cancer: impact in quality of life. Qual Life Res 1993;2:13-22.

[11] Sarna L, Brecht M-L. Dimensions of symptom distress in women with advanced lung cancer: a factor analysis. Heart Lung 1997;26:23-30.

[12] Sarna L, Brown JK, Chernecky C. Quality if life and health status of dyads of women with lung cancer and family members. Oncol Nurs Forum 2006;33:1109-16.

[13] Sarna L, Cooley ME, Chernecky C. Quality of life and meaning of illness of women with lung cancer. Oncol Nurs Forum 2005;32:E9-19.

[14] Cooley ME, Short T, Moriarty H. Symptom prevelence, distress and changes over time in adults receiving treatment for lung cancer. Psycho-Oncology 2003;12:694-708.

[15] Miaskowski C. Gender differences in pain, fatigue, and depression in patients with cancer. J Natl Cancer Inst 2004;32:139-43.

[16] Oh E-G. Symptom experience in Korean adults with lung cancer. J Pain Symptom Manage 2004;28:133-9.

[17] Hopwood P, Stephens RJ. Symptoms at presentation for treatment in patients with lung cancer: implications for the evaluation of palliative treatment. Br J Cancer 1995;71:633-6.

[18] Ouellette D, Desbiens G, Edmond C, Beauchamp G. Lung cancer in women compared with men: stage, treatment, and survival. Soc Thoracic Surg 1998;66:1140-4.

[19] Krech RL, Davis J, Walsh D, Curtis EB. Symptoms of lung cancer. Palliative Med 1992;6:309-15.

[20] de Perrot M, Licker M, Bouchardy C, Usel M, Robert J, Spiliopoulos A. Sex differences in presentation, management, and prognosis of patients with non-small cell lung carcinoma. J Thoracic Cardiovascular Surg 2000;119:21-6.

[21] Earle C. Outcomes research in lung cancer. J Natl Cancer Inst 2004;33:56-77.

[22] Sechzer JA, Rabinowitz VC, Denmark FL, McGinn MF, Weeks BM, Wilkens CL. Sex and gender bias in animal research and in clinical studies of cancer, candiovascular disease, and depression. Ann N Y Acad Sci 1994;736:21-48.

[23] Eastwood J-A, Doering LV. Gender differences in coronary artery disease. J Cardiovascular Nurs 2005;20:340-51.

[24] Tishelman C, Degner L, Rudman A, Bertilsson K, Bond $R$, Broberger $E$, et al. Symptoms in patients with lung carcinoma distinguishing distress from intensity. Cancer 2005;104:2013-21.
[25] Young A, de Haes H, Curran D, Fayers P, Brandberg Y. Guidelines for assessing quality of life in EORTC clinical trials. EORTC Quality of Life Study Group; 1999.

[26] Aaronson NK, Ahmedzai S, Bergman B, Bullinger M, Cull A, Duez $\mathrm{NJ}$, et al. The European organization for research and treatment of cancer QLQ-C30: a quality-of-life instrument for use in international clinical trials in oncology. J Natl Cancer Inst 1993;85:365-76.

[27] Bergman B, Aaronson NK, Ahmedzai S, Kaasa S, Sullivan M. The EORTC QLQ-LC13: a modular supplement to the EORTC core quality of life questionnaire (QLQ-C30) for use in lung cancer clinical trials. Eur J Cancer 1994;30A:635-642.

[28] Fayers P, Aaronson NK, Bjordal K, Curran D, Groenvold M. EORTC QLQ-C30, scoring manual. 2nd ed. EORTC Quality of Life Study Group; 1999.

[29] Osoba D, Rodrigues G, Myles J, Zee B, Pater J. Interpreting the significant of changes in health-related quality-of-life scores. J Clin Oncol 1998;16:139-44.

[30] Beckles MA, Spiro SG, Colice GL, Rudd RM. Initial evaluation of the patient with lung cancer. Chest 2003;123:97S-104S.

[31] Michelson H, Bolund C, Nilsson B, Brandberg Y. Health-related quality of life measured by the EORTC QLQ-C30. Reference values from a large sample of the Swedish population. Acta Oncol 2000;39:477-84.

[32] Nicholas DR. Men, masculinity, and cancer: risk-factor behaviors, early detection, and psychosocial adaptation. J Am College Health 2000;49:27-39.

[33] Skrede K. Levekår i tre kvinnegenerasjoner (Living Conditions in Three Generations of Women). In Oslo: Senter for kvinneforskning, Universitetet i Oslo; 1996.

[34] Orrevall Y, Tishelman C, Herrington MK, Permert J. The path from oral nutrition to home parenteral nutrition: a qualitative interview study of the experiences of advanced cancer patients and their families. Clin Nutr 2004;23:1280-7.

[35] Orrevall Y, Tishelman C, Permert J. Home parenteral nutrition: a qualitative interview study of the experiences of advanced cancer patients and their families. Clin Nutr 2005;24:961-70.

[36] Strasser F, Binswanger J, Cerny T, Kesselring A. Fighting a losing battle: eating-related distress of men with advanced cancer and their female partners. A mixed-methods study. Palliative Med 2007;21:129-37.

[37] Metoder för behandling av långvarig smärta: En systematisk litteraturöversikt (Treatment methods for chronic pain: a systematic review). In. Stockholm: SBU- Statens beredning för medicinsk utvärdering (The Swedish Council on Technology Assessment in Health Care); 2006.

[38] Courtenay WH. Constructions of masculinity and their influence on men's well-being: a theory of gender and health. Social Sci Med 2000;50:1385-401.

[39] Population Statistics. In: Statistics Sweden, Statistiska Centralbyrån; 2006.

[40] Guyatt G, Osoba D, Wu A, Wyrwich K, Norman G. Methods to explain the clinical significance of health status measures. Mayo Clin Proc 2002;77:371-83.

[41] King MT. The interpretation of scores from the EORTC quality of life questionnaire QLQ-C30. Quality Life Res 1996;5:555-67. 